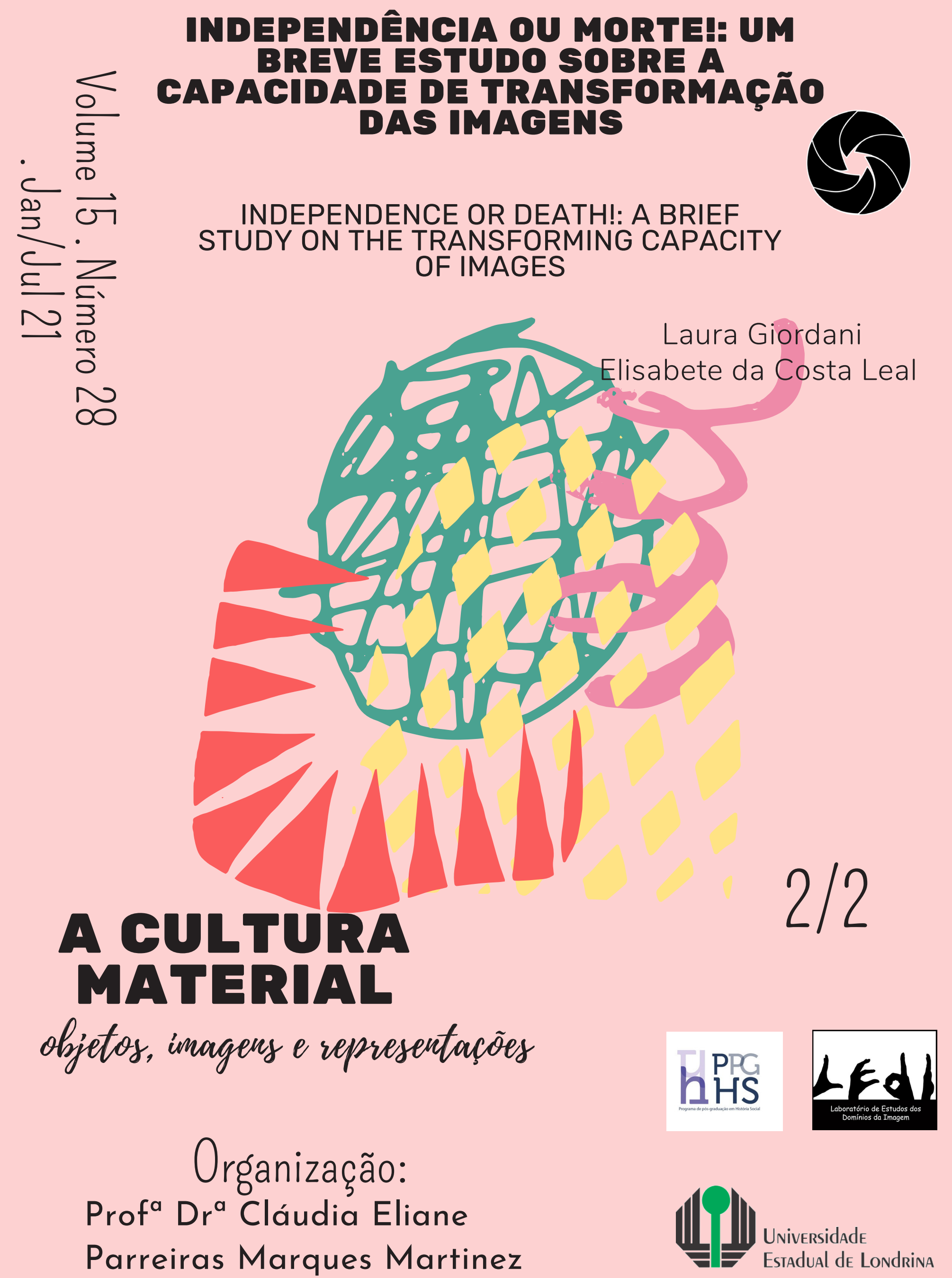




\section{INDEPENDÊNCIA OU MORTE!: UM BREVE ESTUDO SOBRE A CAPA- CIDADE DE TRANSFORMAÇÃO DAS IMAGENS}

\section{INDEPENDENCE OR DEATH!: A BRIEF STUDY ON THE TRANSFOR- MATION CAPACITY OF IMAGES}

\author{
Elisabete da Costa Leal ${ }^{1}$ \\ Laura Giordani²
}

\begin{abstract}
Resumo: O presente artigo se propõe a discutir a criação de uma narrativa visual elaborada por Pedro Américo na obra Independência ou Morte! (1888), analisando a presença de uma versão dessa imagem na graphic novel Independência ou Mortos (2012). Esse estudo abrange desde a concepção da pintura no século XIX até sua ampla reprodução como principal representação visual da Independência do Brasil no século XX, tornando-se uma espécie de modelo para a ilustração do fato. Assim, espera-se demonstrar como é possível que a pintura tenha encontrado espaço em uma história em quadrinhos do século XXI, mesmo com as duas imagens pertencendo a gêneros de criação artística diferentes e distantes entre si.
\end{abstract}

Palavras-chave: História do Brasil; Cultura Visual; Independência do Brasil; Imagens; Arte Sequencial.

\begin{abstract}
This article aims to discuss the creation of a visual narrative elaborated by Pedro Américo in the work Independência ou Morte! (1888), analyzing the presence of a version of this image in the graphic novel Independência ou Mortos (2012). This study encompasses the conception of painting in the 19th century up to its wide reproduction as the main visual representation of the Independence of Brazil in the 20th century, becoming a kind of model for the illustration of the fact. Thus, it is expected to demonstrate how it is possible that a painting found space in a 21 st-century comic book, even with the two images belonging to different genres of artistic creation which are distant from each other.
\end{abstract}

Keywords: History of Brazil; Visual Culture; Independence of Brazil; Images; Sequential Art.
1 Doutora em História Social pela Universidade Federal do Rio de Janeiro, Rio de Janeiro - RJ. Professora do Departamento de História da UFPel. E-mail: elisabeteleal@ymail.com. ORCID https://orcid. org/0000-00030603-5397.

\footnotetext{
${ }^{2}$ Mestre em História pela Universidade Federal de Pelotas, Pelotas-RS. Professora da Rede Particular do Estado de Santa Catarina. E-mail: lauragiordani@outlook.com. ORCID https://orcid. org/0000-0002-37518829.
} 


\section{INTRODUÇÃO}

O presente artigo analisa a expressão visual sobre o fato histórico da Independência do Brasil na pintura Independência ou Morte! (1888) - também conhecida como O Grito do Ipiranga -, do pintor Pedro Américo, e sua constância na iconografia da História do Brasil, chegando ao século XXI expressa na graphic novel ${ }^{3}$ Independência ou Mortos (2012), roteirizada por Fabio Yabu e ilustrada por Harald Stricker, que teve uma de suas ilustrações inspirada na obra oitocentista. Essa pintura se tornou tão conhecida e difundida que acabou se tornando a "imagem oficial da declaração da Independência", criando um repertório visual a respeito do tema e transformando essa tela do século XIX, e o que ela ilustra, em objeto visual reconhecível e atemporal. Sua novas versões e interpretações, permitiram sua presença em uma história em quadrinhos do século XXI.

Para entender essa viagem no tempo e entre diferentes mídias da tela Independência ou Morte! e para que ela acabasse como inspiração da revista Independência ou Mortos, precisamos compreender que ela foi o resultado da combinação de três fatores: as condições sociais de construção de uma imagem, o poder de mutação da imagem, e a capacidade de linguagem das imagens.

\section{CONSTRUINDO UMA IMAGEM E O QUE A CULTURA VISUAL FALA SOBRE ISSO}

Para entendermos a construção da imagem e suas transformações, situamo-nos no campo da Cultura Visual, isso porque se trata de um campo interdisciplinar, que abrange diferentes possibilidades de temas, fontes e disciplinas em seu estudo, permitindo que pudéssemos analisar as diferentes versões da pintura de Pedro Américo em outras mídias.

Os historiadores John A. Walker e Sarah Chaplin, no livro Visual Culture: an introduction (1997), entendem que todo o tipo de produção que interaja com o sentido da visão está apto a se encaixar como tema de estudo na Cultura Visual, mas ao mesmo tempo questionam e expandem a natureza da disciplina justamente por possuir o termo "cultura" em seu nome, visto que isso pode limitar o campo de estudo (WALKER; CHAPLIN, 1997, p. 2). Essa observação faz sentido, dado que uma das definições de "cultura" que encontramos nos dicionários é "Conjunto dos hábitos sociais e religiosos, das manifestações intelectuais e artísticas, que caracteriza uma sociedade”" ${ }^{4}$, porém, essa definição gramatical é limitadora quando comparada à apresentada por Stuart Hall em
3 Ou "romance gráfico", é uma história em prosa ou romance produzida em quadrinhos. Diferente das histórias em Quadrinhos mais tradicionais, esse formato possui uma história mais longa e densa, geralmente possuindo volume único.

4 Disponível em: https://www.dicio. com.br/cultura/. Acessado em 30 de Novembro de 2017. 
seu livro Cultura e Representação (2016), no qual ele discorre sobre como a cultura é vasta e é algo em constante mudança, possuindo relação ao modo como significados de palavras, símbolos e suas combinações recebem diversas interpretações conforme a convivência de diferentes culturas entre si. Portanto, Cultura Visual pode ser visto como um meio de estudar as manifestações do visual tendo como base o que está sendo dado a ver e as condições de sua produção e apreciação.

Com isso em mente, precisamos considerar a época e a intencionalidade da criação da tela Independência ou Mortos! quando nos dispomos a estudar seu impacto e transformações. Isso posto, é importante lembrar que Pedro Américo iniciou a elaboração da pintura mais de cinquenta anos após o acontecimento da Independência do Brasil, e não foi por acaso. A tela foi uma encomenda do governo paulista, que na época estava investindo na construção do Museu do Ipiranga (atual Museu Paulista), um espaço que tinha como objetivo celebrar e firmar o Sete de Setembro como o limiar do Império. O quadro seria colocado no Salão de Honra do museu. A construção desse espaço era, aparentemente, uma tentativa de fortalecer o papel político da monarquia, que estava perdendo forças para as ideias republicanas, com a figura da Família Real e do Imperador perdendo influência e aliados. Pedro Américo, que já era um artista conhecido, foi contratado para elaborar a pintura.

No século XIX, o gênero artístico consagrado como "Pintura Histórica", no qual os artistas se propunham a elaborar obras que reproduzissem um acontecimento da História, era o de maior complexidade e prestígio. Os pintores recebiam uma grande pressão dos críticos e do público a respeito dessas obras, visto que era esperado que houvesse uma "reprodução fiel" do evento histórico. Por isso, precisavam elaborar uma vasta pesquisa no acontecimento e uma excelente apresentação estética, atendendo às exigências dos críticos e do encomendante da pintura, caso houvesse um.

Pedro Américo era um pintor experiente no gênero da Pintura de História e sabia o que era esperado de seu trabalho quando assinou o contrato para elaborar a imagem da Independência em 1886: não era para apenas ser uma representação do Sete de Setembro, tinha que simbolizar o início e a glória do Império brasileiro. Devia fazer com que a imagem de Dom Pedro I - o primeiro imperador, o libertador do Brasil, o pai do atual governante do país - inspirasse coragem, nacionalismo e lembrasse o expectador do que a monarquia havia feito pelo povo. A imagem precisava inspirar nacionalidade e o orgulho de ser brasileiro através da figura do Imperador.

Em seu relato a respeito do processo de elaboração do quadro, Pedro Américo conta que realizou uma extensa pesquisa para que pudesse recriar o dia 7 de setembro de 1822, buscando retratos dos presentes no acontecimento para colocá-los na cena e averiguou os tipos de vestimenta que estariam disponíveis a Dom Pedro I (OLIVEIRA; 
MATTOS, 1999, p. 75). Ao mesmo tempo, ele tinha consciência que não conseguiria reproduzir com precisão um evento que aconteceu meio século antes, e dizia que "a realidade inspira, e não escraviza o pintor" (AMÉRICO, apud OLIVEIRA; MATTOS, 1999, p. 19), e que era o dever do artista apresentar algo para que o público pudesse contemplar sobre o fato histórico. Em outras palavras, o pintor de História deveria se basear nos fatos da realidade, mas ao mesmo tempo, deveria embelezar o evento e demonstrar ao espectador o que ele representa no sentido moral. É seguro dizer, portanto, que Américo sabia que ele havia sido contratado para mostrar ao espectador uma imagem da Independência que inspirasse nacionalismo e admiração à monarquia, algo que não poderia ser atingido com a representação de Dom Pedro I montado em uma mula e em trajes civis. Por isso, em Independência ou Morte! (Imagem 1), ele ilustrou o Monarca e a sua comitiva em bons cavalos e trajes solenes, pois precisava que estes estivessem apresentados à altura da ocasião.

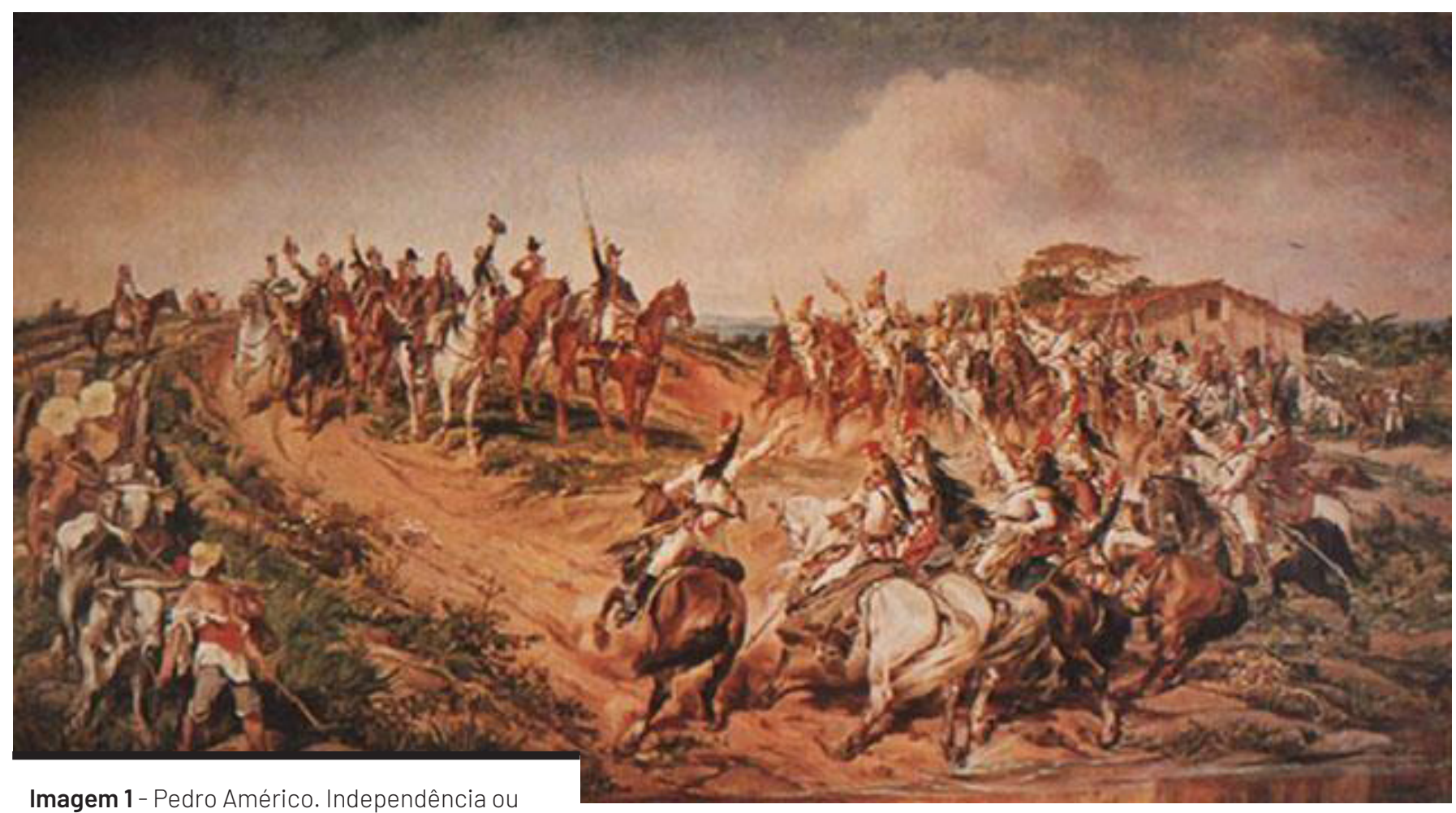
Morte! [0 Grito do Ipiranga]. Óleo s/tela, 1888, 414×760cm. Fonte: Acervo do Museu Paulista. Disponível em: <http://enciclopedia.itaucultural.org.br/obra1431/independencia-ou-morte>. Acesso em: 20 de Março de 2017

Na pintura, a cena se passa em um descampado às margens do Rio Ipiranga, com Dom Pedro I localizado no centro da imagem montado em seu cavalo e brandindo seu sabre, sugerindo que havia acabado de bradar "Independência ou Morte!" ou que estava no meio de fazê-lo. Esse posicionamento é importante, visto que ao colocá-lo em uma posição elevada indica que ele estava acima do homem comum, apresentando-o como 
o protagonista e destacando seus atos. Uma comitiva de soldados acompanha o Imperador e observa o momento do grito de Independência, alguns reagindo ao acontecimento, com seus cavalos em movimento, ou brandindo a sua espada junto a Dom Pedro I, ou realizando os dois atos. Além dos soldados, temos alguns civis que testemunham a cena, que estão mais às margens da pintura, em menor número e caracterizados como trabalhadores do campo, pois aparecem ilustrados usando roupas simples e manuseando ferramentas de trabalho, como se a presença dessas pessoas comuns indicasse a participação do povo na Independência, ou até mesmo a sua salvação pela Monarquia. O resultado é um tanto militarizado, sugerindo que Dom Pedro I e sua comitiva estavam prontos para entrar em combate a qualquer momento, apresentando-o como um protetor e um homem de ação.

O resultado do quadro é belíssimo e sua operação visual e historiográfica é exitosa sendo difícil separar a imagem ilustrada dos relatos de como a Declaração da Independência ocorreu. Isso não se dá apenas pelo trabalho de Américo, apesar de ser um dos fatores, há uma série de circunstâncias que influenciaram essa associação: a pintura foi encomendada pelo governo, o que dá um ar de oficialidade à produção da obra. Além disso, sua presença e disponibilidade para visitação no Salão de Honra do Museu de Ipiranga, sendo a obra mais destacada do acervo, criou a ilusão desta ser a mais importante obra entre tudo que estava exposto, devido à importância do fato ilustrado. A sintonia entre esses fatores fez com que a pintura praticamente passasse a ser concebida como uma reprodução verídica do Sete de Setembro de 1822

As historiadoras Cecília de Salles Oliveira e Claudia Valladão, no livro O Brado do Ipiranga (1999), observam que não tardou para a pintura alcançar uma posição de notoriedade na visualidade da Independência do Brasil, citando como exemplo o caso da inauguração de um monumento em comemoração ao centenário da Independência em 1920. Nele, as autoras falam sobre como Afonso de Escragnolle Taunay, o então diretor do Museu Paulista, não era a favor do projeto de Ettore Ximenes, o ganhador do concurso para a construção do monumento, por acreditar que o trabalho era parecido demais com o quadro de Pedro Américo, o que em sua opinião diminuiria o valor do monumento em favor ao da pintura (OLIVEIRA; MATTOS, 1999, p. 64). Em pouco menos de 30 anos de existência, a pintura de Pedro Américo havia conseguido deixar uma forte marca na imagem da Independência do Brasil. 

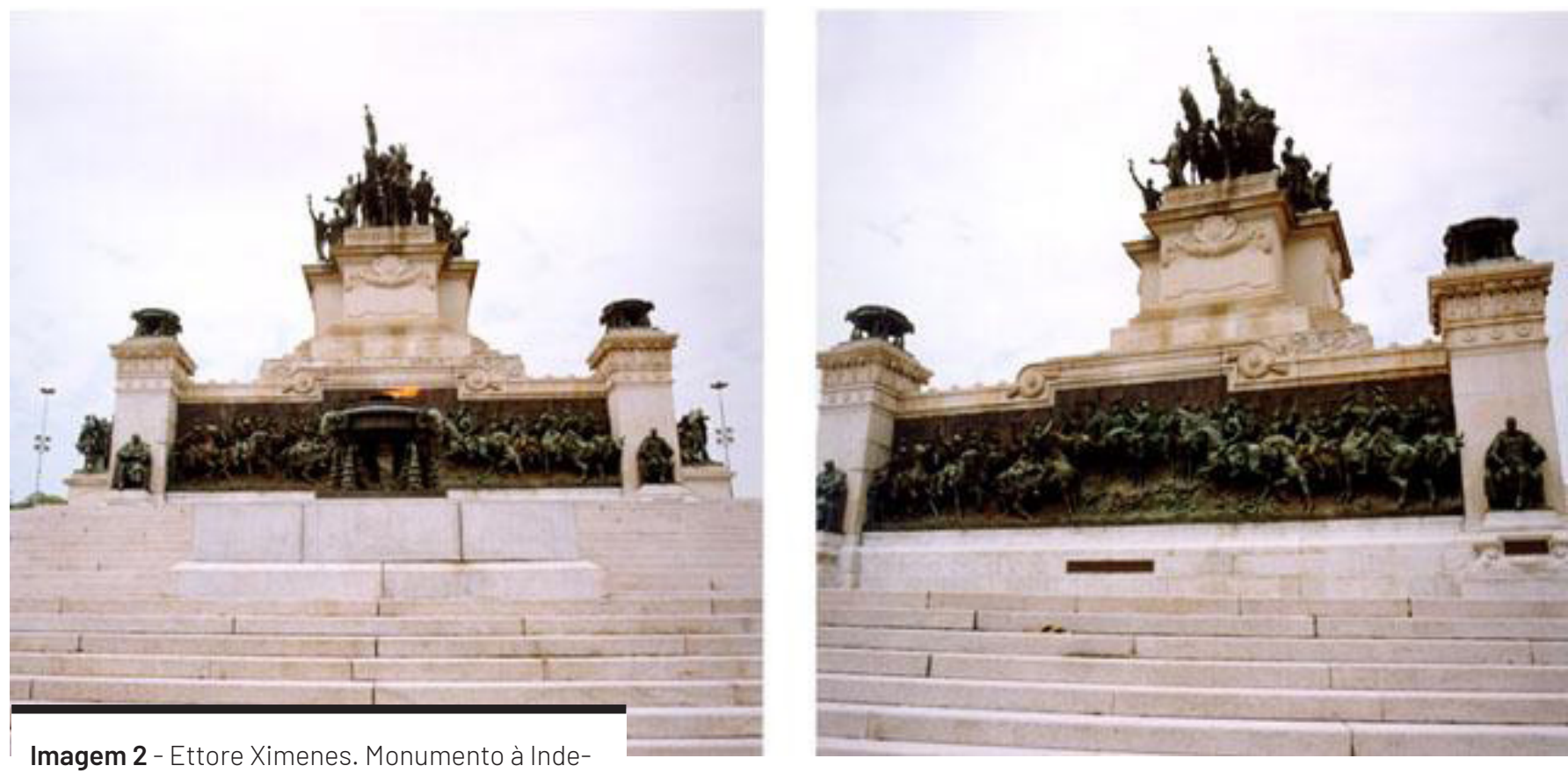

pendência do Brasil. Bronze, 1922. Fonte: Enci-

clopédia Cultural do Itaú. Disponível em: <http://

enciclopedia.itaucultural.org.br/obra25185/

monumento-a-independencia>. Acesso em: 10

de Agosto de 2020.

As circunstâncias mudaram na ocasião do sesquicentenário da Independência. Durante o ano de 1972, a imagem de Dom Pedro I e do quadro foi largamente utilizada na celebração e produção do fato, aparecendo nas mais diversas mídias e meios: revistas, jornais, cadernos escolares, cartazes, livros didáticos, calendários, cédulas de dinheiro, selos, cartões telefônicos, etc. (SCHIAVINATTO, 2002, p. 92). A alta difusão da imagem nessa época fez com que ela passasse de "a melhor imagem que representa a Independência" para "a imagem referência da Independência", tanto que é muito difícil que algum brasileiro não tenha ao menos um grau de familiaridade com ela. Por ser tão significativa para o nosso entendimento da Independência, ela acaba se tornando o modelo para a criação de novas reproduções - seja na literatura, na televisão, no cinema, nos quadrinhos, etc. - a respeito do episódio.

Veja a seguir alguns exemplos de reproduções do quadro Independência ou Morte! e de imagens criadas a partir dele: 


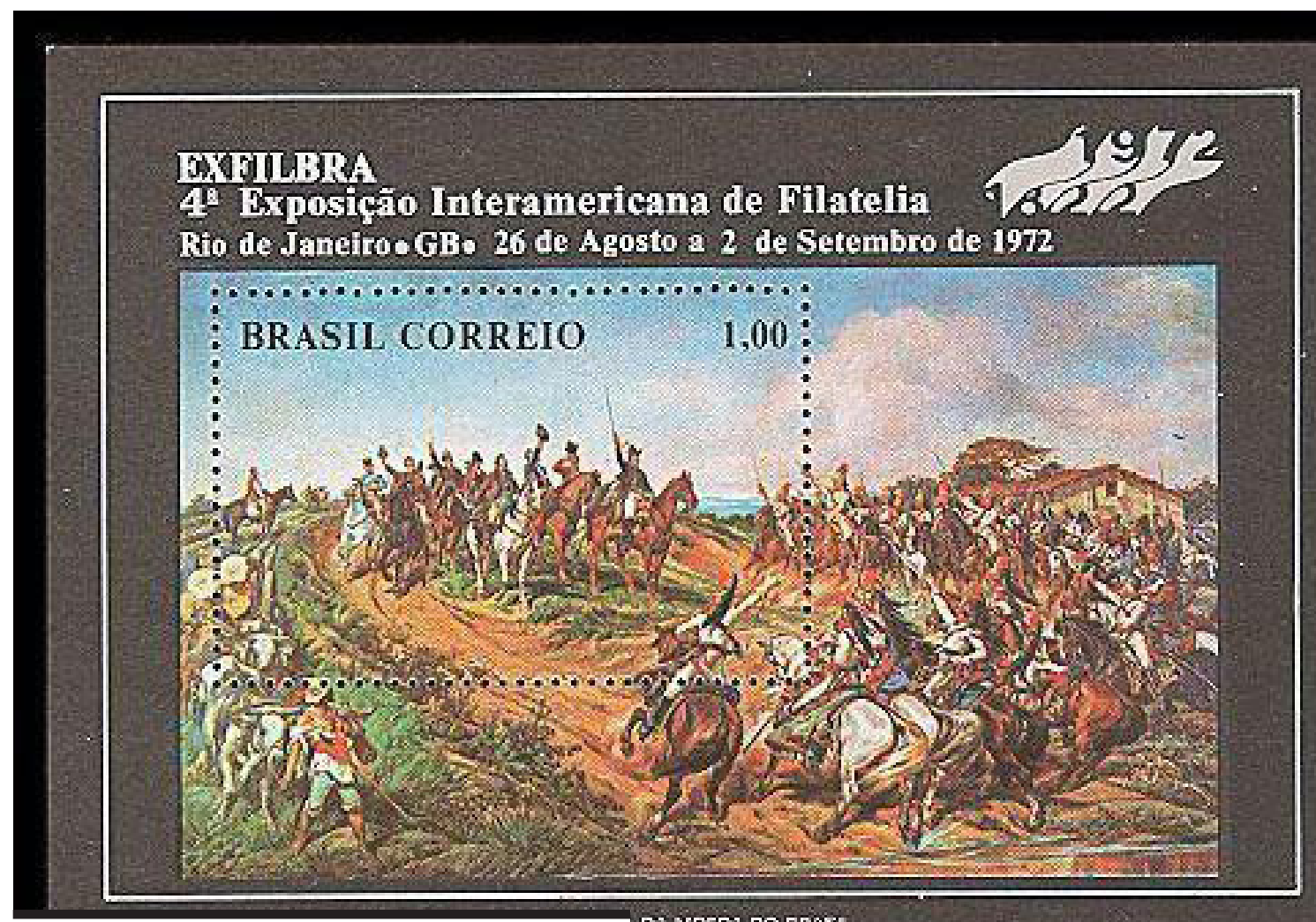

Imagem 3 - Autor desconhecido. Selo comemorativo dos 150 anos da Independência. Filatelia, 1972. Fonte: Associação Filatélica e Numismática de Brasilia. Disponível em: <http://afnb-bsb-colecionismo.blogspot.com.br/2010/08/ independencia.html >. Acessado em 28 de junho de 2017.

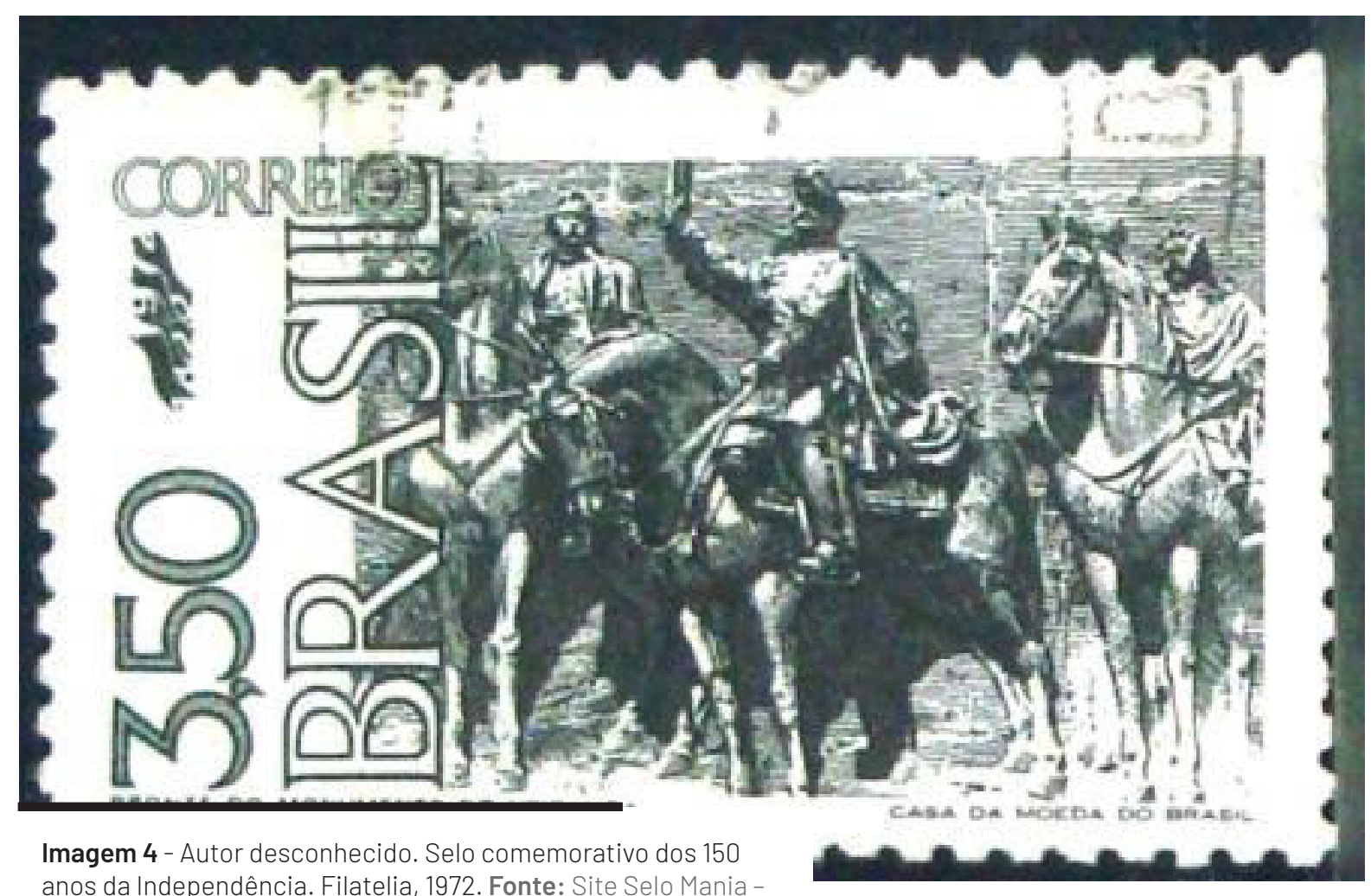

anos da Independência. Filatelia, 1972. Fonte: Site Selo Mania -

Filatelia Nacional e Internacional. Disponível em: <https://www. selomania.com.br/selos-colecionaveis/brasil-filatelia/temas-1/ centen\%C3\%A1rios-anivers\%C3\%A1rios/1972-grito-do-ipiranga-3-detail.html>. Acessado em 15 de setembro de 2020 


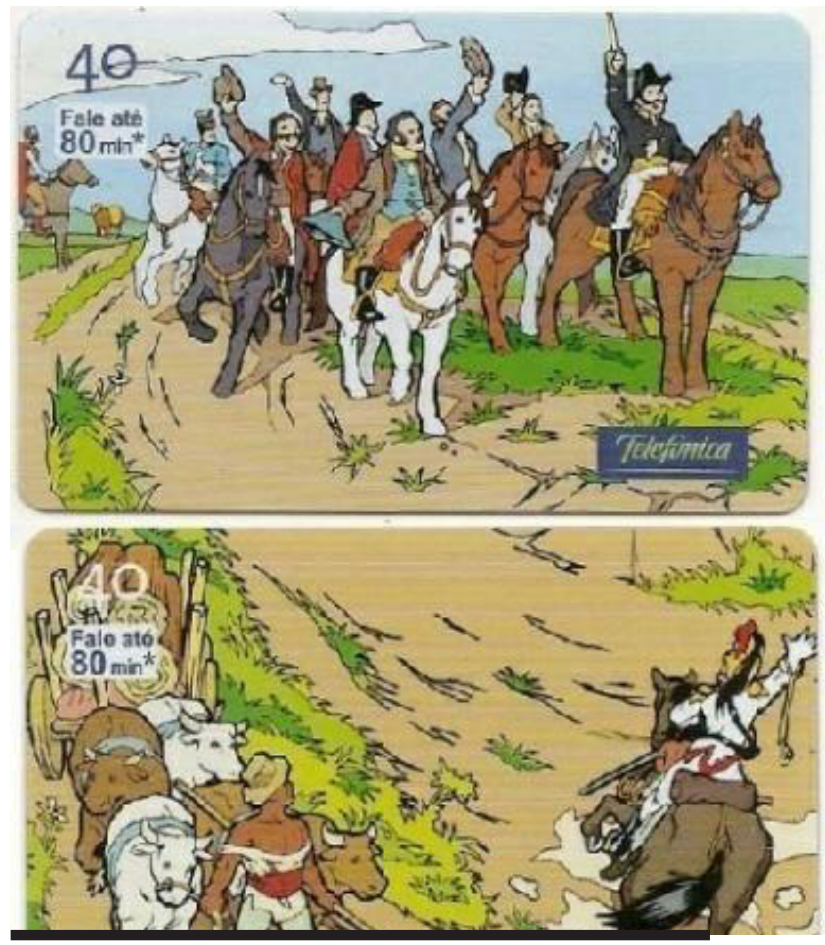

Imagem 5 - Telebrás. Cartão telefônico com a temática da Independência. Telecartofilia, 1966. Fonte: Associação Filatélica e Numismática de Brasillia. Disponível em: <http://afnb-bsb-colecionismo.blogspot.com.br/2010/08/independencia.html>. Acessado em 28 de junho de 2017.
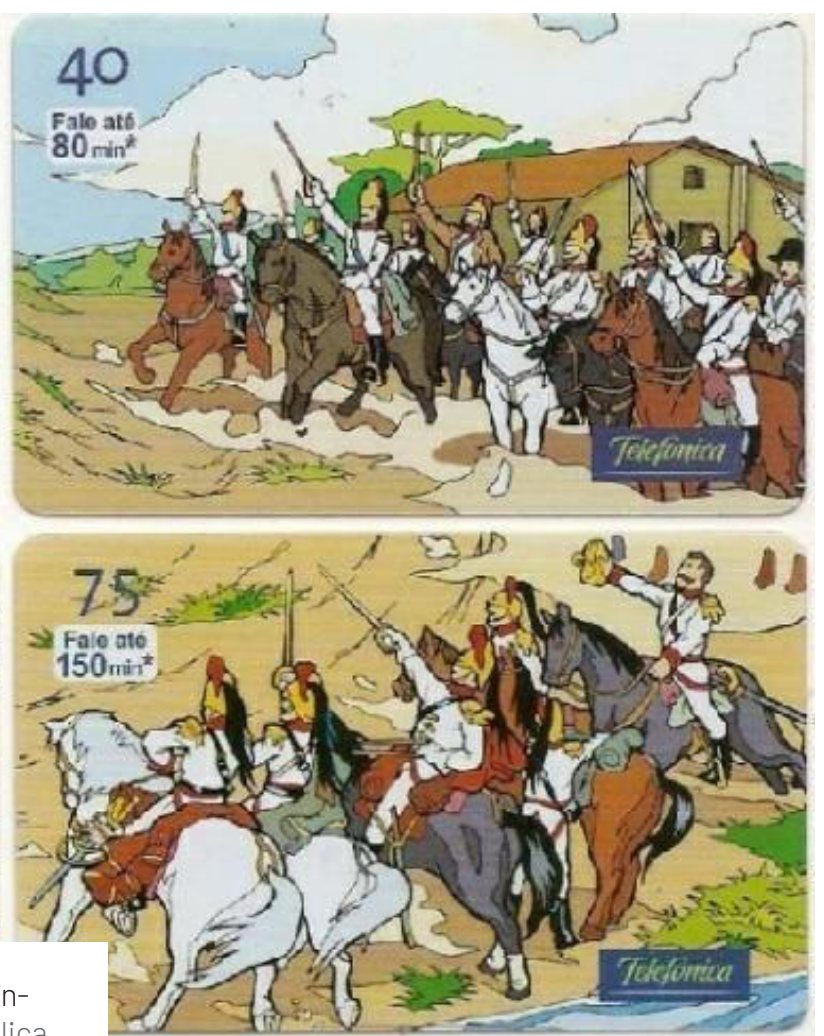

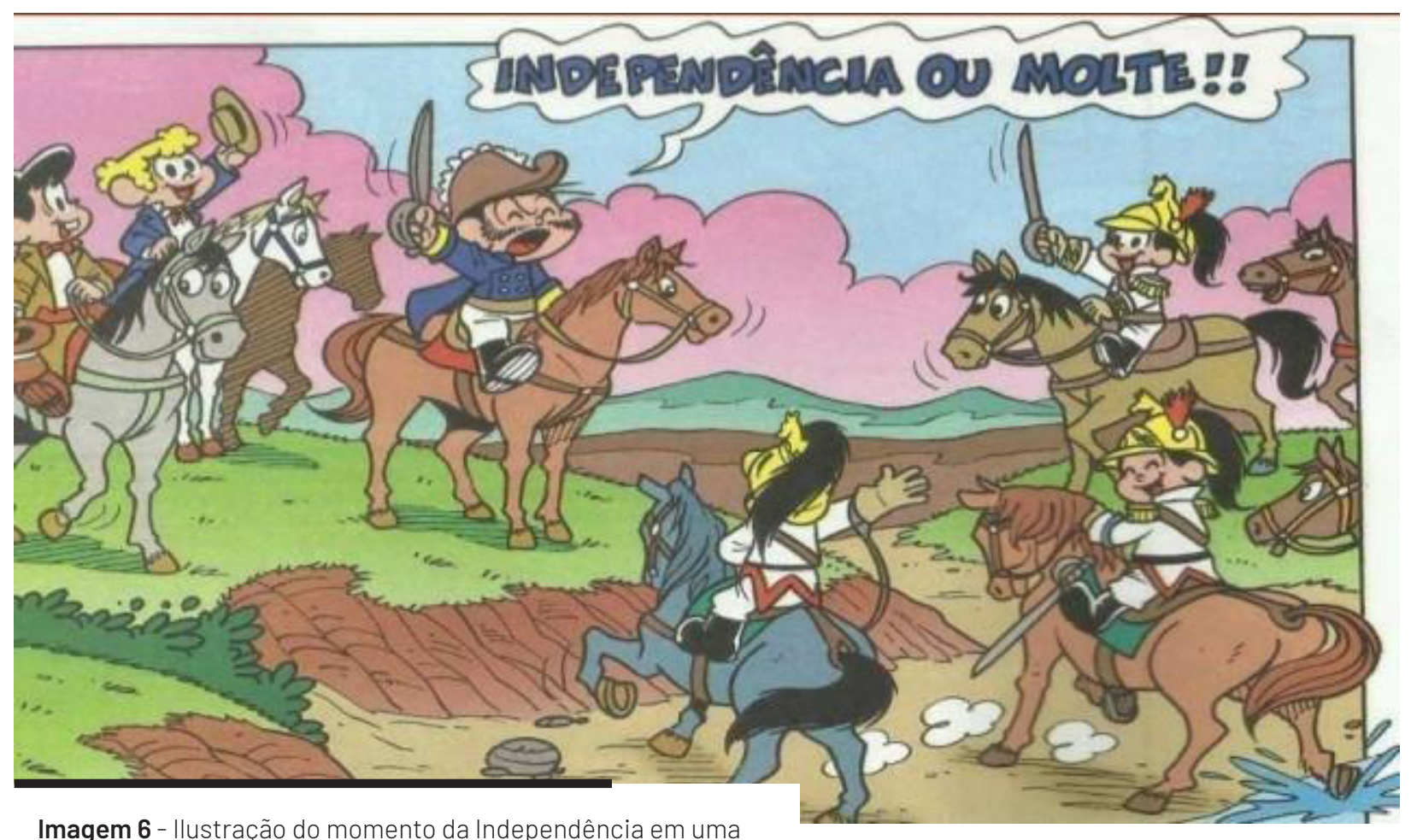

Imagem 6 - Ilustração do momento da Independência em uma revista em quadrinhos brasileira. Fonte: Maurício de Sousa. Você Sabia? - Independência do Brasil. São Paulo: Ed. Globo, 2003. p.37. Disponivel em: <http://www.espacoeducar. net/2012/08/voce-sabia-independencia-dobrasil.html>. Acessado em 20 de dezembro de 2017. 
As imagens acima são exemplos do poder de sua mutabilidade. Apesar de nem todas elas serem realmente uma cópia exata ou uma transformação total da pintura, a mudança de mídia e meio de exposição são completamente drásticos em comparação com a da obra original. O meio acadêmico do século XIX de apreciação da arte no Brasil, no qual a obra de Pedro Américo se consagrava, previa um sistema de regras rígidas a respeito da produção e da distribuição da arte, o que, de certa forma, poderia limitar a capacidade de atingir público. Conforme o século XX avançou, essas regras da criação e distribuição de arte se tornaram cada vez menos rígidas, chegando ao ponto em que encontrar novos usos para imagens já existentes passou a ser algo aceitável, desde que não ferisse os direitos autorais.

A questão de direitos autorais é controversa e delicada no caso de criação de novas imagens a partir de uma já existente, muitas vezes dependendo no modo como o artista da obra original se sente a respeito do uso de seu trabalho. No caso da pintura de Pedro Américo, não se encaixa a discussão de direitos autorais, visto que a obra Independência ou Morte! possui uma existência separada a do artista devido a sua importância na cultura e na História brasileira. Portanto, é perfeitamente aceitável que outras pessoas utilizem a imagem criada por Américo para originar novas ilustrações da Independência, inclusive, considerando a associação entre História e obra, seria estranho se esse não fosse o caso.

A Cultura Visual entende que a imagem é fruto do seu tempo. Segundo Paulo Knauss, essa linha de estudos seria um desdobramento de um movimento geral de interrogação sobre a cultura em termos abrangentes (2006, p. 107), e define os estudos das construções culturais da experiência visual cotidiana, assim como as mídias, representações e artes visuais (2006, p. 108). Nesse sentido, existe um posicionamento político na imagem, expressão de uma cultura, sendo muito mais do que uma alegoria ou um movimento artístico, mesmo que isso não seja aparente.

O que aconteceu com Independência ou Mortos! no decorrer do século XX, e agora no século XXI, foi uma constante tomada de apropriações de diferentes artistas e meios da imagem para a sua criação . As novas obras manteriam o simbolismo original - a Declaração da Independência, porém de uma forma que se encaixaria na narrativa e na linguagem visual propostas pelo autor. A nova imagem pode ser considerada uma obra separada da sua inspiração, mas que não é completamente independente dela.

INDEPENDÊNCIA OU MORTOS E A NARRATIVA VISUAL DA GRAPHIC NOVEL

A graphic novel Independência ou Mortos - roteirizada por Fabio Yabu, usando 
o pseudônimo Abu Fobiya, e ilustrada por Harald Stricker foi publicada em setembro de 2012 pela editora Nerdbooks - se propõe a trazer mais do que apenas uma nova ilustração da Independência à tona ou de ser uma outra de imagem comemorativa entre as demais.

Como o próprio título da graphic novel sugere, a história se baseia na História do Brasil - mais especificamente dos anos 1807 até por volta de 1822 -, recontando os eventos que levaram à Independência do Brasil, narrados por Dom Pedro I, que assume o papel de protagonista na trama. Ela não apenas se apropria da narrativa historiográfica do fato, como também adiciona o monstro "zumbi" como personagem, apresentado como um dos antagonistas da narrativa, junto com os portugueses. $\mathrm{O}$ próprio título da graphic novel faz um jogo de palavras, utilizando a frase atribuída a Dom Pedro I no momento da Independência, "Independência ou Morte!", a qual se transformou em "Independência ou Mortos!", referindo-se claramente aos zumbis presentes na trama.

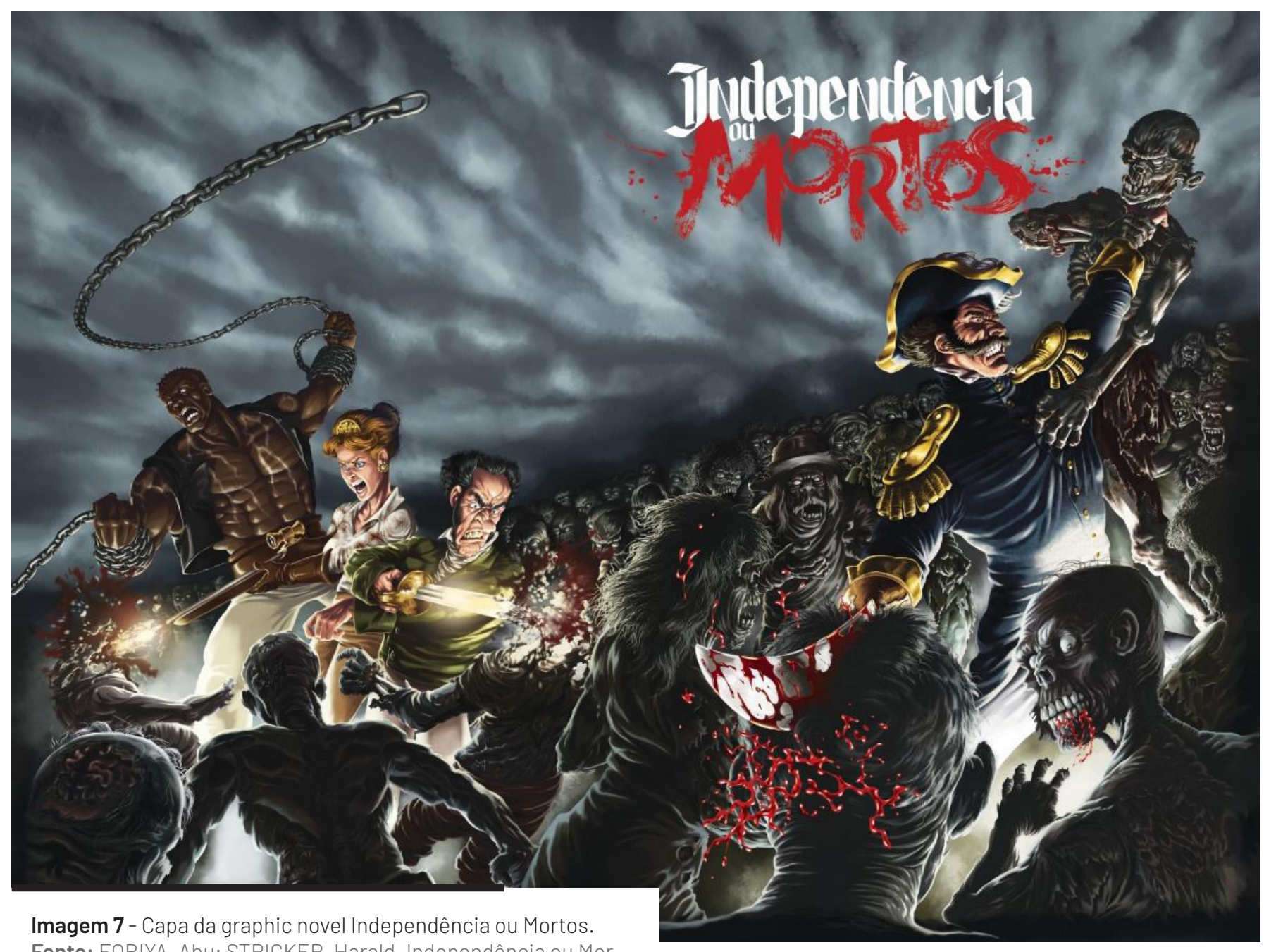
Fonte: FOBIYA, Abu; STRICKER, Harald. Independência ou Mortos. Curitiba: Nerdbooks, 2012. Capa. 
Em um programa de podcast, o Nerdcast, que pertencente aos editores e donos da Nerdbooks - Alexandre Ottoni e Deive Pazos -, a edição 327, "Making of de Independência ou Mortos", foi publicada no dia de lançamento da revista a fim de trazer publicidade à obra, contando com a presença dos autores, que explicaram o processo criativo. No programa, foi revelado que a ideia sempre foi fazer uma obra de quadrinhos com algum tema da "História do Brasil" e que utilizar zumbis era um projeto antigo dos editores da revista. A escolha do conteúdo "Independência do Brasil" ocorreu quando Yabu sugeriu o título "Independência ou Mortos", sem dar mais nenhuma explicação, porém a ideia foi imediatamente aceita, pois, nas palavras de Pazos, "o título é autoexplicativo, e a ideia se vende sozinha" (OTTONI; GERPE, 2012).

A inclusão do personagem "zumbi" não foi por acaso, visto que na época da elaboração da obra, o personagem estava muito popular nas mídias de entretenimento e na cultura pop, devido à popularidade da série de televisão adaptada da série de quadrinhos de 2003, The Walking Dead, dos autores Robert Kirkman e Tony Moore, produzida desde o 2010. Mesmo antes da série ser lançada, o gênero de filmes, jogos e histórias de terror com zumbis já existia e fazia sucesso, visto os filmes do diretor George Romero ${ }^{5}$ - como Despertar dos Mortos (1978) e A Noite dos Mortos Vivos (1968) - nos anos 90, e a franquia de videogames da empresa Capcom Resident Evil - que teve seu primeiro título lançado em 1996 e seu mais recente em 2020. O gênero recebeu uma renovação nas mídias durante os anos 2000 com filmes como Extermínio (2002) e Zumbilândia (2009), porém, ao que parece, recebeu mais notoriedade e mais produções sobre ele após o lançamento da série.

A princípio, a inclusão na ficção de um monstro tão fantasioso como o zumbi acabaria por prejudicar a integridade da narrativa de uma obra que toma como tema acontecimentos históricos, todavia, por se tratar de literatura, Independência ou Mortos não possui o compromisso de seguir fielmente a História. Adicionado a isso, o zumbi é apresentado no enredo do quadrinho como um dos elementos causadores do desenrolar dos acontecimentos e conflitos políticos entre Portugal e Brasil. A respeito dessa inclusão, Yabu comentou durante o programa que não desejava que o zumbi fosse apenas um elemento do cenário da revista, mas um elemento que fizesse a história se desenrolar, que tivesse um protagonismo na narrativa (OTTONI; GERPE, 2012). Para atingir esse objetivo, o autor fez com que os monstros fossem usados principalmente para o desenvolvimento do personagem de Dom Pedro I, sendo o incentivo para que assumisse as responsabilidades da Coroa e aceitasse o Trono. Em outras palavras, o papel do zumbi em Independência ou Mortos é transformar Dom Pedro I em um herói coroado.

O momento central do título da revista, o momento da Independência do Brasil, acontece na página 107, sendo composto por dois quadros (Imagem 8). A ilustração elaborada por Stricker não deixa completamente explícito sua inspiração no quadro, con-
5 George Andrew Romero (1940-2017) - Diretor de cinema norte-americano consagrado por seus filmes de terror envolvendo zumbis. (Disponivel em: <http:// www.imdb.com/ name/nm0001681/ bio>. Acesso em: 15 jan. 2018 (Tradução das autoras) 
tudo o reconhecimento é entendido por conta da aparência e situação serem familiares.
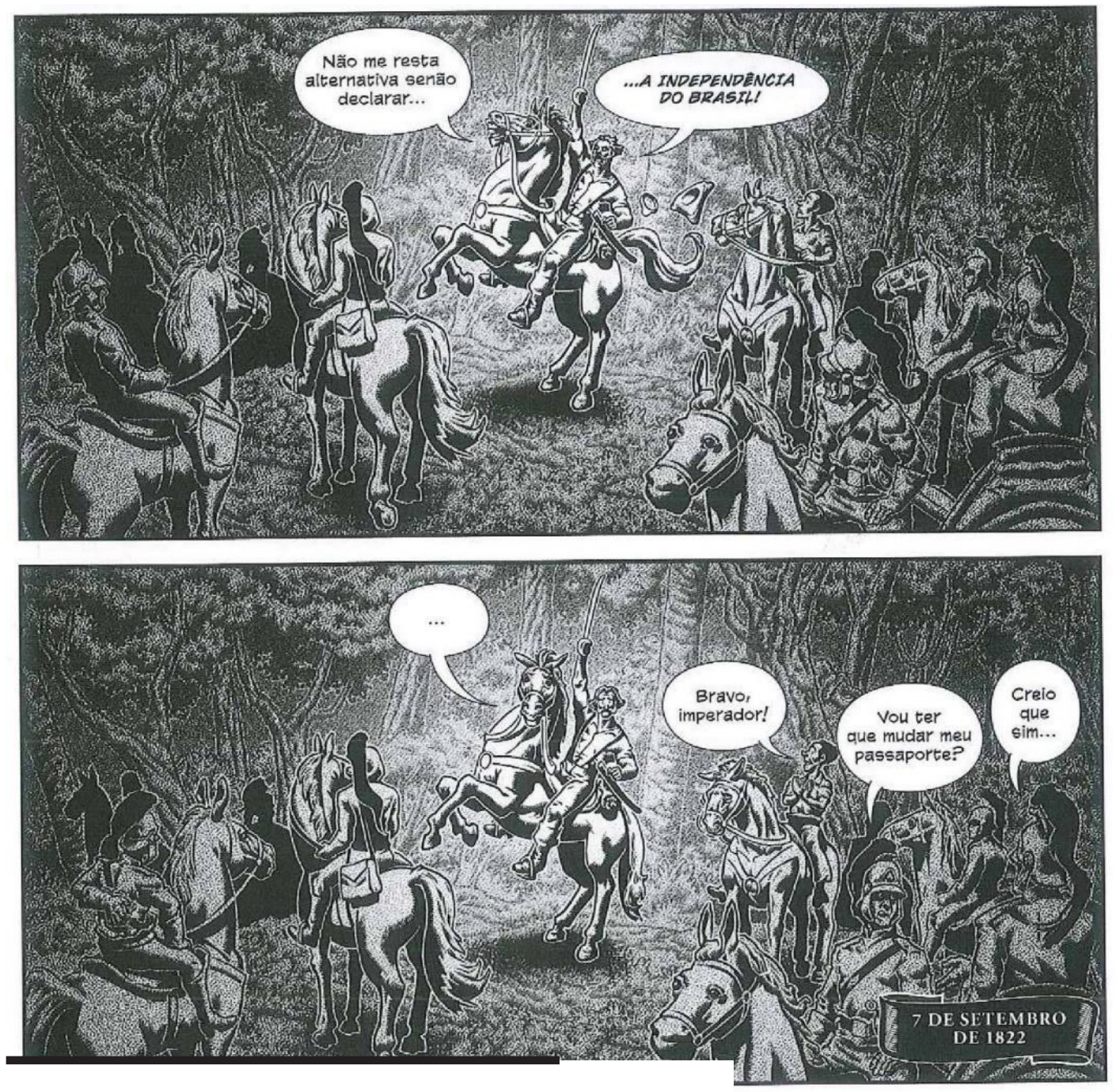

Imagem 8 - Momento em que a independência é declarada no quadrinho Independência ou Mortos. Fonte: FOBIYA, Abu; STRICKER, Harald. Independência ou Mortos. Curitiba: Nerdbooks, 2012, p. 107.

As diferenças entre as Independência ilustradas em Independência ou Morte! e Independência ou Mortos podem ser facilmente listadas:

- O brado do Ipiranga na graphic novel ocorre no interior de uma floresta e não em um descampado às margens do Rio Ipiranga como na pintura, o que significa que o acontecimento ocorreu afastado do local icônico;

- Na graphic novel, o cavalo de Dom Pedro I está sobre as duas patas traseiras, enquanto na pintura, o cavalo está com as quatro patas no chão, não compartilhando da agitação de seu cavaleiro;

- Os cavalos estão voltados para lados diferentes; 
- A comitiva de soldados na pintura reage e compartilha do entusiasmo de Dom Pedro I, enquanto na graphic novel, não há reação daqueles que o acompanham, salvo uma felicitação de um personagem;

- Na graphic novel as vestimentas de Dom Pedro I são humildes quando comparadas à que ele veste na pintura, o que não o identifica visualmente como o líder da comitiva ou como monarca;

- Na pintura, há uma percepção de movimento, pois os soldados se movem ao redor de Dom Pedro I e os cavalos estão ilustrados em agitação, na graphic novel, os espectadores estão estáticos;

- Há mais iluminação na pintura, visto o uso de cores, e ela está em maior uso na figura de Dom Pedro I;

- Apesar de ser uma figura de destaque na área central da cena, Dom Pedro I não se localiza exatamente no centro na pintura, tal como no quadrinho, estando um pouco mais elevado para a esquerda, de modo que ele esteja com uma posição superior do que a dos demais;

- O número de participantes na graphic novel está muito reduzido se comparado à pintura.

Stricker, em entrevista, expressou que, apesar de ser praticamente inevitável usar a pintura como inspiração, sua intenção ao ilustrar o momento da Independência não era de criar mais uma versão visual do quadro de Pedro Américo, mas sim de trazer o que ele procurava inspirar: heroísmo, coragem, rebelião e glória, tudo isso sendo imediatamente rechaçado em prol de continuar com a narrativa na história em quadrinhos (STRICKER, 2017). Embora não seja uma reprodução fiel ao quadro Pedro Américo, a ilustração de Stricker representa o que a pintura deseja inspirar no observador, enquanto os outros exemplos presentes aqui buscavam trazer a familiaridade da imagem.

Mesmo assim, é possível reconhecer semelhanças entre as duas ilustrações:

- Dom Pedro I é o personagem em maior destaque, de modo que a atenção do observador se direcione diretamente a ele, facilitando seu reconhecimento como o protagonista da cena;

- Todos os personagens presentes nas ilustrações estão com sua atenção direcionada a Dom Pedro I. Apesar de simples, esse recurso indica que há o reconhecimento ou, ao menos, a atenção dos expectadores a respeito do ato que Dom Pedro I acaba de realizar;

- Em ambas ilustrações, Dom Pedro I está com a espada desembainhada e ergui- 
da ao ar, um movimento que dá ênfase e um certo tom de ameaça à frase que ficou consagrada à Independência do Brasil;

- O público nas duas imagens é composto basicamente por soldados, o que condiz com a narrativa histórica a respeito do Sete de Setembro: Dom Pedro I acompanhado por uma pequena comitiva de soldados profere o brado do Ipiranga. Portanto, se o objetivo é recriar o momento do modo mais fiel possível, faz-se necessário adicionar esse elemento social à ilustração.

O principal motivo para as diferenças entre as duas imagens existirem se dá por elas pertenceram a duas mídias distintas: enquanto Independência ou Morte! se limita a contar uma história em um único quadro, Independência ou Mortos possui uma sequência de quadros para construir a narrativa até alcançar o ponto da história em que a Independência é declarada.

\section{A INDEPENDÊNCIA DO BRASIL EM IMAGENS: PINTURA E QUADRINHOS}

Todas as imagens são capazes de apresentar uma narrativa quando colocadas em seu devido contexto. Os objetos de estudo presentes aqui se encaixam no gênero de narrativa histórica: um pertence ao gênero de Pintura Histórica, e o outro é uma literatura histórica. Ambos podem ser considerados narrativas ficcionais. Hayden White descreve as particularidades e desafios da construção de uma narrativa histórica, no seu livro Trópicos do Discurso: Ensaios sobre a Crítica da Cultura (2014), argumentando que há poucas diferenças entre narrativas literárias e narrativas históricas e como as duas frequentemente se encontram. Seguindo essa lógica, por mais que o texto histórico elaborado por um historiador - que realizou uma extensa pesquisa para coletar o maior número possível de informações sobre o evento e tomar uma postura de neutralidade -, o resultado ainda será um texto em formato informativo que busca criar uma narrativa coesa a respeito de um evento do passado, em outras palavras, um texto com o objetivo de narrar de maneira informativa um evento histórico irá possuir elementos de ficção em sua forma de se expressar.

Tal como já foi observado, Pedro Américo tinha consciência de que estava criando uma versão não tão exata da Independência, visto que considerava parte do trabalho do artista do gênero de Pintura Histórica o dever de se desviar um pouco da precisão histórica a favor do seu embelezamento. Outra questão que ele tinha que considerar era a narrativa visual a ser montada em Independência ou Morte!, que por si só é um desafio quando supomos que a capacidade de narrativa de uma pintura é limitada, pois têm como espaço para seu desenvolvimento apenas um quadro.

Essa limitação pode ser facilmente contornada se concebemos que as pinturas de 
História geralmente ilustram o momento de clímax do evento histórico e por ser esperado que os espectadores da obra sejam informados a respeito do tema da obra que estão apreciando. Ainda resta a questão de fazer com que a representação desse clímax apresente sua própria sequência narrativa. $\mathrm{O}$ modo que Pedro Américo compôs a cena de Independência ou Morte! - considerando as suas proporções, com quase cinco metros de altura por oito metros de largura - permitiu a apresentação de vários fluxos de leitura da imagem, oferecendo várias linhas de leitura através do arranjo de cores e iluminações. O observador poderia: primeiro ver Dom Pedro I no centro da tela, circular seu olhar ao redor do quadro e absorver o impacto de sua ação ao observar as ações dos outros indivíduos retratados; iniciar a leitura a partir de uma das extremidades do quadro, tanto pela esquerda ou pela direita, que a posição e curso dos elementos e personagens irão direcionar o olhar para Dom Pedro I. De qualquer forma, o primeiro Imperador sempre será a ênfase da leitura, assegurando o seu papel como o protagonista da cena e destacando-se como realizador do grande ato.

Independência ou Mortos pertence a um gênero completamente diferente, entrando na chamada Arte Sequencial, que tem como definição: "Imagens pictóricas e outras justapostas em sequência deliberada destinadas a transmitir informações e/ou produzir uma reposta no espectador" (MCCLOUD, 2005, p. 20). A história em quadrinhos é o exemplo mais conhecido desse gênero. Por ser uma história em quadrinhos, a narrativa da imagem do Sete de Setembro se diferencia muito da presente em Independência ou Morte!, pois enquanto a pintura representa o clímax da História da Independência, na graphic novel o momento da declamação sequer é o auge da narrativa, sendo mais próximo de um evento de estabelecimento de conflito na história, já que inicia uma série de acontecimentos no enredo. Tanto é que o brado do Ipiranga não acontece nessa cena. Isso ocorre porque a graphic novel de Yabu e Stricker se propõe a contar uma narrativa fantasiosa da História da Independência do Brasil e, portanto, reconhece o acontecimento do brado do Ipiranga como um ponto de conflito marcante, sem o indicar como seu desfecho ou clímax, mas sim como um fato de importância e gerador de conflitos.

De certa forma, é possível dizer que Independência ou Mortos possui maior liberdade criativa na forma de se comunicar com seus espectadores do que Independência ou Morte!. Além de possuir o recurso de conseguir utilizar a imagem e o texto, as histórias em quadrinhos contam com a capacidade do leitor de entender os signos de expressões, emoções e situações a partir da arte apresentada por meio de personagens, balões de diálogo e fundos, e confia na sua habilidade de preencher as lacunas entre os quadros. Essa forma de criar uma narrativa a partir de imagens permite que os artistas possam utilizar os mais diferentes estilos de arte para construir sua história, desde que empreguem expressões consideradas universais para exibir acontecimentos, tal como Scott McCloud explica em sua obra Desvendando os Quadrinhos (2005), ao ilustrar 
como uma expressão de facial de neutralidade pode ser reconhecível com traços simples (MCCLOUD, 2005, p. 45).

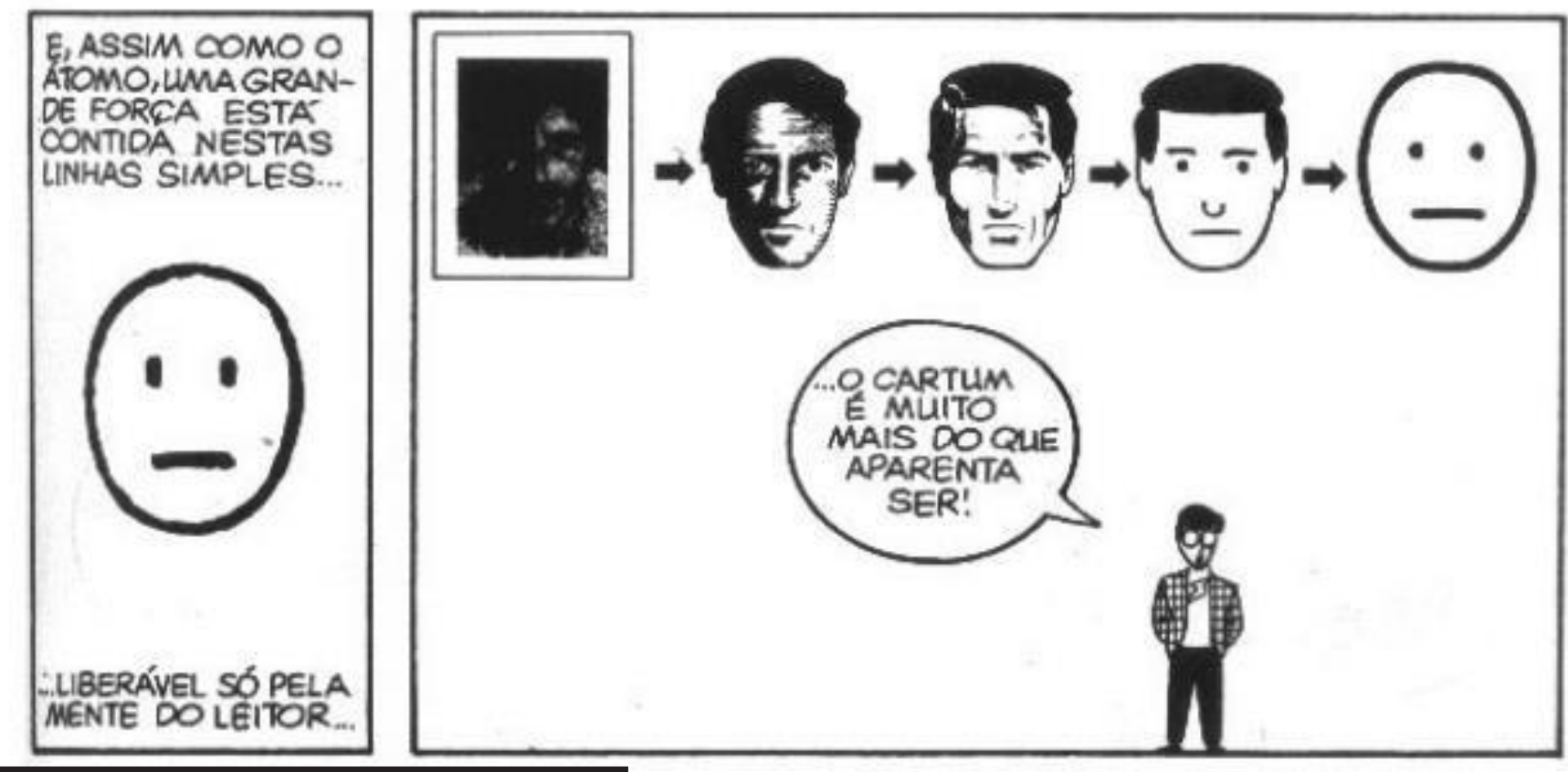

Imagem 9 - Scott McCloud mostra a capacidade do ser humano de entender o que está sendo ilustrado via a arte dos quadrinhos. Fonte: MCCLOUD, Scott. Desvendando os Quadrinhos.

São Paulo: Mbooks, 2005, p. 45

A obra de McCloud tem como foco explorar a competência narrativa dos quadrinhos, expondo como a mídia se aproveita da tendência do olho humano em buscar familiaridades, e acaba evidenciando como somos capazes de ler imagens e compreender o que elas estão a comunicar mesmo sem o auxílio do texto, haja vista que somos orientados por símbolos. Assim, os quadrinhos criam uma narrativa complexa e capaz de tornar razoável a combinação de elementos fantasiosos com elementos realistas sem comprometer sua integridade.

Essa liberdade possui desvantagens. O trabalho de Pedro Américo era limitado tanto por conta da natureza do projeto como pelo seu espaço criativo. No entanto, Independência ou Morte! faz um trabalho muito melhor em expor seu conteúdo sem contexto. A ilustração é construída de modo que seja fácil reconhecer que se trata de uma imagem de um acontecimento importante, pois mesmo que a obra seja apresentada sem seu título a alguém que a desconhece, é possível identificar elementos marcantes: um indivíduo em um local elevado demonstra sua importância e chama a atenção; seu braço elevado mostra que ele está exaltado; as movimentações dos aparentes soldados em seus cavalos indica agitação e reconhecimento de uma ordem ou o fim de um discurso; a atenção dos demais espectadores voltada a esse indivíduo determina que o que ocorreu 
foi algo bastante chamativo.

Por outro lado, caso apenas os dois quadros da página 107 da graphic novel Independência ou Mortos forem apresentados sem nenhum outro contexto a um observador que desconhece a obra, ele será incapaz de identificar a cena como o momento-chave de uma narrativa ou até mesmo como um acontecimento notável. O máximo que poderia ser reconhecido seria uma situação engraçada e caricata. Isso se deve justamente por se tratar de uma narrativa sequencial, que mesmo com o contexto presente, para entender os acontecimentos da página 107 é necessário que o leitor possua conhecimento a respeito dos eventos ocorridos na história até então.

Por necessitar de pouco contexto para seu entendimento, Independência ou Morte! faz que a relação de influenciador e influenciado com as imagens que vieram após a sua exposição se transpareça bem. De certa forma, o conhecimento da existência da pintura de Pedro Américo é um pré-requisito para que todas as imagens que ilustram a Independência que vieram após a ela façam sentido, se não teríamos em mãos um aglomerado de figuras mostrando um homem em um cavalo gritando para um grupo de pessoas sem qualquer motivo aparente.

Essa necessidade de contexto se fortalece em Independência ou Mortos, onde a narrativa presente nas páginas anteriores precisa ser levada em conta na hora de entendermos o que está ocorrendo na página 107. Por outro lado, se considerarmos essa circunstância de narrativa, as imagens da Independência na graphic novel pouco dependem da existência do quadro de Américo para que o evento se mostre como um acontecimento importante, pois o que define a identidade visual de um evento notável está presente na ilustração: uma frase de efeito bradada por um personagem erguendo um sabre com a presença de testemunhas.

\section{CONSIDERAÇÕES FINAIS}

Apesar de suas diferenças, as duas obras se propõem a contar, a sua maneira, o fato da Independência do Brasil, utilizando os recursos disponíveis aos seus autores no momento. Contudo, a presença da pintura de Américo na graphic novel de Yabu e Stricker demonstra como a obra chegou a um ponto em que ela se relaciona à História do Brasil de forma quase inseparável. A obra de Américo, com o passar das décadas, se associou com força à narrativa da História, processo longo e significativo, visto que a pintura demonstra como nós gostamos de ver a História e não como ela realmente se passou, o que simboliza que seu papel de redesenhar o passado foi bem-sucedido e continua expondo resultados, mesmo após terem sido desmentidos.

O poder na determinação de narrativa visual do trabalho de Américo pode ser 
considerada como um fator decisivo para a construção de Dom Pedro I como um personagem heroico. Os relatos e narrativas históricas são capazes de apresentar o protagonismo de indivíduos por trás dos acontecimentos da História, realizar essa exposição em formato de imagem faz que a ligação entre obra e observador ocorra mais rapidamente do que em texto.

As circunstâncias por trás da elaboração da pintura contribuíram muito para ela ser o que é hoje, pois o cuidado de criar uma narrativa e representação visual marcantes, junto com os seus privilégios de exposição, permitiu que, mais de cem anos depois de sua concepção, ela mantivesse a sua notoriedade até os dias atuais.

Independência ou Mortos não seria a mesma obra se não fosse Independência ou Morte!. A intenção da graphic novel de Yabu e Stricker era a construção da imagem de Dom Pedro I como um herói e o colocar nessa posição, demonstrando que, ao desafiar seu pai e as decisões das Cortes, ele acabou por enfrentar um inimigo poderoso mesmo em desvantagem em uma disputa, a qual levou até o fim. Esse protagonismo de Dom Pedro I e seu chamado para a ação na narrativa no ato heroico do brado do Ipiranga tem bases na imagem que Américo elaborou, tanto que apresenta na sua própria versão da pintura o momento da Declaração de Independência que, apesar de não ser tão grandiosa quando a obra original, mostra o respeito e reconhecimento por ela como a imagem do Sete de Setembro.

Enquanto em uma narrativa historiográfica voltada a acadêmicos exploraria a História do Brasil com seriedade, apontando absurdos e/ou particularidades de indivíduos e acontecimentos históricos, o meio da construção imagética de Independência ou Morte! e Independência ou Mortos trazem mais personalidade à Independência, mostrando como ela pode ser transformada desde uma imagem gloriosa e inspiradora a uma história de terror cômico. O mais curioso sobre essas duas obras é como a existência de uma enriquece a outra, seja como objeto inspirado ou como objeto inspirador da outra. 


\section{REFERÊNCIAS}

FOBIYA, Abu; STRICKER, Harald. Independência ou Mortos. Curitiba: Nerdbooks, 2012.

GIORDANI, Laura. Cultura Visual e História: conexões entre o quadro Independência ou Morte! e a graphic novel Independência ou Mortos (Séculos XIX a XXI). 2018. Dissertação (Mestrado em História - UFPel), Pelotas, 2018.

HALL, Stuart. Cultura e Representação. (Organização e revisão Técnica Arthur Ituassu). Tradução Daniel Miranda e William Oliveira. Rio de Janeiro: Ed. PUC-RIO, 2016.

KNAUSS, Paulo. O desafio de fazer História com imagens: arte e cultura visual. Revista ArtCultura, Uberlândia, v. 8, n. 12, 2006, p. 97-115.

McCLOUD, Scott. Desvendando os Quadrinhos. São Paulo: Mbooks, 2005.

OLIVEIRA, Cecília Helena de Salles; MATTOS, Claudia Valladão de (orgs.). O Brado do Ipiranga. São Paulo: Editora da Universidade de São Paulo, 1999.

OTTONI, Alexandre; GERPE, Deive Pazos. Nerdcast 327 - Making of de Independência ou Mortos. 2012. Disponível em:<http://jovemnerd.com.br/nerdcast/ nerdcast-327-making-of-independencia-oumortos $>$. Acessado em 20 de agosto de 2016.

SCHIAVINATTO, Iara Lis. A Praça Pública e a Liturgia Política. Caderno Cedes, Campinas, vol. 22, n. 50, 2002, p. 81-99.

STRICKER, Harald. Entrevista concedida a Laura Giordani. Pelotas, 25 de julho de 2017.

WALKER, John A; CHAPLIN, Sarah. Visual Culture: an introduction. Manchester University Press, 1997.

WHITE, Hayden. Trópicos do Discurso: Ensaios sobre a Crítica da Cultura. Tradução de Alípio Correia de Franca Neto. São Paulo: Editora da Universidade de São Paulo, 2014. 